\title{
Factors Associated with Success Rate for Tuberculosis Treatment in Hospital: A Directly Observed Treatment Short Tuberculosis Prevention Strategy in Central Java
}

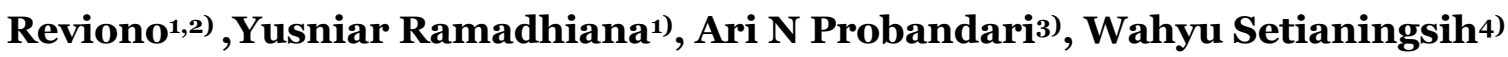 \\ 1)Department of Pulmonology and Medical Respiration, Faculty of Medicine, \\ Universitas Sebelas Maret/ Dr. Moewardi Hospital, Surakarta \\ 2) Department of Pulmonology, Dr. Moewardi Hospital, Surakarta \\ 3)Department of Public Health and Medical Prevention, Universitas Sebelas Maret \\ 4)Provincial Health Office of Central Java
}

\begin{abstract}
Background: Tuberculosis (TB) is a major health problem throughout the world. Hospitals and pulmonary clinics contribute significantly to the number of patients from all positive smear cases. Hospital performance in TB control is assessed using treatment success rates. The purpose of this study is to find out an overview of hospital performance factors that influence the success of hospitals in TB control in Central Java.

Subjects and Method: The study design was descriptive analytical epidemiology with a retrospective cohort design. The samples were taken in total sampling. The subjects were 158 hospitals in Central Java Province that used the DOTS strategy. The variable assessment instrument from the 2010 TB Sub-Directorate of Ministry of Health's checklist was taken in January-February 2018. The data were linked to TB data from the Central Java Provincial Health Office in 2013 and 2016. Treatment success rates were stated to be good if the value was $\% 85 \%$

Results: There were 110 hospitals with complete data in 2013 and 2016. Good success rates (>85\%) in 2013 were achieved by 59 (53.60\%) hospitals in 2013, in 2016 it decreased, only 43 (39.10\%) hospitals were achieved. There was no significant relationship between the commitment and organization of the DOTS Hospital team, treatment, medical supervision, internal / external networks, and health facilities with the success rate of TB treatment,in which in this study, the value of $p>0.05$. The type of hospital was significantly associated with treatment success rates in 2013, in which the lower type of hospital, the better the success rate of TB treatment.

Conclusion: Because of the low number of hospitals that achieve good success rates $(>85 \%)$, more detailed identification of risk factors is needed.
\end{abstract}

Keywords: tuberculosis, success rate, hospitals

\section{Correspondence:}

Reviono. Department of Pulmonology and Medical Respiration, Universitas Sebelas Maret Jl. Ir. Sutami 36A, Surakarta 57126, Central Java. Email: reviono@staff.uns.ac.id. Mobile: +62818474671.

\section{BACKGROUND}

Tuberculosis (TB) is a major health problem throughout the world. Tuberculosis is an infectious disease caused by a Mycobacterium tuberculosis complex infection (Doucette et al, 2015). The TB epidemic is bigger than previously thought. New TB cases in 2015 are estimated to be 10.4 million worldwide, equivalent to 142 cases/100,000 residents, with details of men with 5.9 million (56\%), women with 3.5 million (34\%), and children with 1.0 million (10\%) cases. Six countries accounted for $60 \%$ of new cases, namely India, Indonesia, China, Nigeria, Pakistan, and South Africa (WHO, 2016).

Kundu et al. (2016) examined TB control programs in India in 2016 about improving the TB classification of private sector cases. It was steps for direct and one- 
time sensitization of private practitioners (in clinics, hospitals, and private practices). The results were that the TB notification cases from the private sector increased from 341 in 2013 to 4,049 at the end of March 2015. The conclusion that state-level active initiatives towards private sector increased in TB cases.

The proportion of confirmed pulmonary TB patients in Indonesia experienced a significant increase from 1999 to 2003 from $7 \%$ to $13 \%$. This indicator tends to decline from 2003 to 2014, then again increases to $14 \%$ in 2015. The incidence of $\mathrm{TB}$ in Indonesia is 125 events/100,000 population in 2015 (Ministry of Health, 2016).

The number of cases and deaths from TB is still high. The incidence of TB and deaths from TB continues to fall globally. The incidence of TB that is increasing globally successfully shows a downward trend of $2 \%$ per year in 2012. The mortality rate was successfully reduced by $45 \%$ compared to 1990 (Doucette K et al, 2015). The rate of reduction in TB incidence was only $1.5 \%$ from 2014 to 2015 . This number needs to be accelerated to $4-5 \%$ per year by 2020 to reach the first milestone of End TB Strategy (WHO, 2016).

Pulmonary hospitals and clinics contribute significantly to the number of patients, namely $51 \%$ of all cases and $56 \%$ of positive new BTA cases in 2004. This progress has caused other problems. Differences in character between public health workers and specialist hospitals show a bias in population-based patient care with individuals. The over-diagnosis of cases of negative smear sputum in hospitals shows general resistance to behavioral changes by doctors (Irawati et al, 2007).

TB control programs in all countries are designed by the public sector and are mostly carried out through the public sector or the National Tuberculosis Programs
(NTP). National Tuberculosis Programs are very important but have not fully developed TB treatment and control. The publicprivate mix (PPM) approach was introduced in several developing countries during the late 1990s. The PPM component includes public hospitals, private hospitals, pulmonary clinics, health centers, and private practices. The World Health Organization (WHO) through its programs places PPM as an important component to support the success of TB prevention in the world. There are two indicators of TB control nationally, namely the number of new patients finding positive smear TB (Case Detection Rate $=$ CDR) and treatment success rates (Success Rate $=$ SR) (Irawati, et al, 2007). The purpose of this study is to assess the performance of hospitals in TB control by using treatment success rates.

\section{SUBJECTS AND METHOD \\ 1. Study design \\ The study design used was descriptive ana- lytic epidemiology with a retrospective cohort design.}

\section{Population and samples}

The study was conducted at the Central Java Provincial Health Office in JanuaryFebruary 2018. The study population was a hospitals in Central Java Province that carried out the DOTS program. The instrument used was a 2010 TB Sub-Directorate of the Ministry of Health, represented by data from the Provincial Health Office Central Java. Sampling technique in quantitative study was carried out by means of total sampling from all hospitals in Central Java Province using the DOTS strategy and included in the Ministry of Health TB Subdit view list in 2010 amounting to 158 hospitals.

The inclusion criteria in this study were public hospitals, military / police, and the private sector in Central Java Province 
that used the DOTS strategy and were included in the TB List of the Ministry of Health's Subdit in 2010. The exclusion criteria if there were no 2013 or 2016 SITT reports or results zero report.

\section{Study variables}

The independent variables in this study were commitment and organization of the DOTS Hospital team, treatment, supervision of medication, internal/external networks, health facilities, hospital types. It is said to be good if the value is $\geq 80 \%$. The dependent/dependent variable in this study was the success rate (SR) of the hospital in TB treatment. The indicator for treatment success was $>85 \%$. The treatment success rate reaches the target if the value was $\geq 85$

\section{Research Ethics}

Ethical clearance was obtained from the Ethics Eligibility Committee of the Faculty of Medicine, UNS Surakarta with no: 100 / II / HREC / 2018. The research permit

Table 1. The characteristics of the data are based on the 2010 Ministry of Health TB Subdit's checklist

\begin{tabular}{lccc}
\hline \multicolumn{1}{c}{ Variable } & \multirow{2}{*}{$\mathrm{N}$} & Good & Poor \\
\cline { 3 - 4 } & & $\mathrm{n}(\%)$ & $\mathrm{n}(\%)$ \\
\hline Commitment and organization & 110 & $15(13.64)$ & $95(86.36)$ \\
Treatment & 110 & $10(9.09)$ & $100(90.91)$ \\
Treatment supervision & 110 & $18(16.36)$ & $92(83.64)$ \\
Internal / external network & 110 & $11(10.00)$ & $99(90.0)$ \\
Facilities of equipment facilities & 110 & $19(17.27)$ & $91(82.73)$ \\
\hline
\end{tabular}

The variable value from the checklist was said to be good if it reached $\geq 80 \%$. Not many of 110 hospitals achieved a score of $>$ $80 \%$. Based on table 1, it is known that the achievement of commitments, treatment, treatment supervision, internal/external networks and equipment facilities are from the Central Java Provincial Government no: 070/3958 / 04.5 / 2017.

\begin{tabular}{l}
\hline RESULTS \\
\hline Based on the results of the study, 158 \\
hospitals were included in the Ministry of \\
Health's list of views. Not all 158 hospitals \\
made a report to the Integrated Tuber- \\
culosis Information System (SITT). Data in \\
2013 showed that there were 37 hospitals \\
with no data reports and in 2016, there \\
were seven hospitals with no data reports. \\
There were several hospitals that were not \\
operating anymore. There were four hos- \\
pitals whose case reporting rates are zero. \\
After processing, the complete data was \\
obtained in 110 hospitals. Table 1 describes \\
the characteristics of the data based on the \\
Ministry of Health TB Subdit view list.
\end{tabular}

mostly considered poor. From each variable, only less than 20\% reached a good score, the variable facility equipment facilities were the highest, the hospitals which were considered to have good equipment facilities were 19 (17.27\%).

Table 2. Characteristics of the data based on success rates

\begin{tabular}{lcc}
\hline Success rate & $\mathbf{N}$ & \% \\
\hline Success rate 2013 & 110 & \\
$<85 \%$ & 51 & 46.40 \\
$>85 \%$ & 59 & 53.60 \\
Success rate 2016 & 110 & \\
$<85 \%$ & 67 & 60.90 \\
$>85 \%$ & 43 & 39.10 \\
\hline
\end{tabular}


The success rate is said to be good if the value is $85 \%$. $<85 \%$ success rate is called bad. In 2013 the success rate of $\geq 85 \%$ TB treatment was 59 hospitals (53.6\%). In 2016 the success rate of TB85\% TB treatment was 43 hospitals (39.1\%). There is a decrease in the number of hospitals that can achieve good success rates (85\%). Table 2 shows the characteristics of the data base on the success rate.
The results of the achievement of the success rate of treatment of TB hospital which was declared good in 2013 were achieved by $51(46.40 \%)$ hospitals. The majority of types of hospitals were type C, which was $54.5 \%$ and minorities with type A, which were $1.8 \%$. The details of the type of hospital were explained in table 3 .

Table 3. Characteristics of research data based on hospital types

\begin{tabular}{ccc}
\hline Type of hospital & $\mathbf{N}$ & \% \\
\hline D & 25 & 22,7 \\
C & 60 & 54,5 \\
B & 23 & 20,9 \\
A & 2 & 1,8 \\
\hline
\end{tabular}

\section{Factors that influence the success rate of $T B$ treatment}

Based on data from the Indonesian Ministry of Health TB Subdit view list in 2010, there were five factors that influence the success rate of hospitals in TB control programs. These five factors are the commitment and organization of the DOTS Hospital team, treatment, supervision of medication, internal/external networks, and health facilities. The five factors are assessed in relation to the success rate of TB treatment, as explained in table 4. Based on table 4, it is known that commitment and organization, treatment, treatment supervision, internal/external networks, and equipment facilities were not significantly related to the success of TB treatment, because they were obtained $\mathrm{p}>0.050$.

Table 4. The risk of success in TB treatment in 2013 was based on commitment, treatment, supervision of treatment, internal / external networks, and facilities for equipment facilities

\begin{tabular}{|c|c|c|c|c|}
\hline \multirow{2}{*}{ Variable } & \multicolumn{2}{|c|}{ SR_2013 } & \multirow{2}{*}{ OR (95\%CI) } & \multirow{2}{*}{$\mathbf{p}$} \\
\hline & $<85 \%$ & $>85 \%$ & & \\
\hline \multicolumn{5}{|l|}{ Commitment } \\
\hline$<80 \%$ & 42 & 54 & $0.43(0.13-1.38)$ & 0.150 \\
\hline$>80 \%$ & 9 & 5 & & \\
\hline \multicolumn{5}{|l|}{ Treatment } \\
\hline$<80 \%$ & 45 & 55 & $0.54(0.14-2.05)$ & 0.509 \\
\hline$>80 \%$ & 6 & 4 & & \\
\hline \multicolumn{5}{|l|}{ Treatment supervision } \\
\hline$<80 \%$ & 45 & 48 & $1.71(0.58-5.03)$ & 0.320 \\
\hline$>80 \%$ & 6 & 11 & & \\
\hline \multicolumn{5}{|l|}{ Internal/external network } \\
\hline$<80 \%$ & 46 & 53 & $1.04(0.29-3.63)$ & 0.949 \\
\hline$>80 \%$ & 5 & 6 & & \\
\hline \multicolumn{5}{|l|}{ Facilities } \\
\hline$<80 \%$ & 39 & 52 & $0.43\left(0.15^{-1.21}\right)$ & 0.107 \\
\hline$>80 \%$ & 12 & 7 & & \\
\hline
\end{tabular}


Based on table 4, it is known that the commitment variable tends to be a protective factor for the success of pulmonary TB treatment with $\mathrm{OR}=0.43$ (o.13-1.38) $(\mathrm{OR}<1)$. Treatment variables tend to be a protective factor for the success of pulmonary $\mathrm{TB}$ treatment with $\mathrm{OR}=0.54$ (0.142.05) (OR <1). The results of the fisher exact test obtained a value of $\mathrm{p}=0.509$, which means that there was no significant relationship between treatment and the success of TB treatment in 2013. Treatment control variables tend to be a supporting factor/risk of successful pulmonary TB treatment $(\mathrm{OR}=1.72 ; 95 \% \mathrm{CI}=0.58$ to 5.03). The variable external internal net- work tends to be a supporting factor / risk of the successful treatment of pulmonary $\mathrm{TB}(\mathrm{OR}=1.04 ; 95 \% \mathrm{CI}=0.29$ to 3.64$)$. Variables of equipment facilities tend to be a protective factor for the success of pulmonary $\mathrm{TB}$ treatment $(\mathrm{OR}=0.44 ; 95 \% \mathrm{CI}=$ 0.16 to 1.21 ).

Based on table 5 , it is known that commitment and organization, patient discovery, treatment, treatment supervision, internal/external networks, and equipment facilities were not significantly related to the success of TB treatment in 2016 (p>0.050). Categorical analysis was explained in table 5 .

Table 5. The risk of success in TB treatment in 2016 based on variable commitment, treatment, supervision of medication, internal / external networks, and facilities for equipment facilities.

\begin{tabular}{|c|c|c|c|c|}
\hline \multirow{2}{*}{ Variable } & \multicolumn{2}{|c|}{ SR_2016 } & \multirow[b]{2}{*}{ OR (95\%CI) } & \multirow[b]{2}{*}{$\mathbf{p}$} \\
\hline & $<85 \%$ & $>85 \%$ & & \\
\hline \multicolumn{5}{|l|}{ Commitment } \\
\hline$<80 \%$ & 59 & 37 & $1.19(0.38-3.72)$ & 0.757 \\
\hline$>80 \%$ & 8 & 6 & & \\
\hline \multicolumn{5}{|l|}{ Treatment } \\
\hline$<80 \%$ & 63 & 37 & $2.55(0.67-9.64)$ & 0.185 \\
\hline$>80 \%$ & 4 & 6 & & \\
\hline \multicolumn{5}{|l|}{ Treatment supervision } \\
\hline$<80 \%$ & 55 & 38 & $0.60(0.19-1.85)$ & 0.374 \\
\hline$>80 \%$ & 12 & 5 & & \\
\hline \multicolumn{5}{|c|}{ Internal/external network } \\
\hline$<80 \%$ & 59 & 40 & $0.55(0.14-2.21)$ & 0.523 \\
\hline$>80 \%$ & 8 & 3 & & \\
\hline \multicolumn{5}{|l|}{ Facilities } \\
\hline$<80 \%$ & 55 & 36 & $0.89(0.32-2.47)$ & 0.825 \\
\hline$>80 \%$ & 12 & 7 & & \\
\hline
\end{tabular}

Commitment tended to be a supporting/risk factor for the success of pulmonary TB treatment $(\mathrm{OR}=1.19 ; 95 \% \mathrm{CI}=0.38$ to 3.72). Treatment variables tended to be a supporting/risk factor for the success of pulmonary $\mathrm{TB}$ treatment $(\mathrm{OR}=2.55 ; 95 \%$ $\mathrm{CI}=0.67$ to 964$)$. Treatment supervision variables tended to be a protective factor for the success of pulmonary TB treatment $(\mathrm{OR}=0.60 ; 95 \% \mathrm{CI}=0.19$ to 1.85$)$. External internal network variables tended to be a protective factor for the success of pulmonary $\mathrm{TB}$ treatment $(\mathrm{OR}=0.55 ; 95 \% \mathrm{CI}=$ 0.13 to 2.21). Fisher exact test results obtained $\mathrm{p}=0.523$, which means that there was no significant relationship between external internal networks and the success of TB treatment in 2016. Variables of equipment facilities tended to be a protective factor for the success of pulmonary TB 
Journal of Epidemiology and Public Health (2019), 4(4): 283-295

https://doi.org/10.26911/jepublichealth.2019.04.04.03

treatment $(\mathrm{OR}=0.89 ; 95 \% \mathrm{CI}=0.32$ to 2.47$)$.

Table 6. The success rate of TB treatment in 2013 and 2016 based on hospital type

\begin{tabular}{|c|c|c|c|c|c|}
\hline \multirow{2}{*}{ Type of hospital } & \multirow{2}{*}{$\mathbf{n}$} & \multicolumn{2}{|c|}{ SR 2013} & \multicolumn{2}{|c|}{ SR 2016} \\
\hline & & Good n (\%) & Poor n (\%) & Good n (\%) & Poor n (\%) \\
\hline Type D & 25 & & & & $16(64.0)$ \\
\hline Type C & 60 & $34(56.7)$ & $26(43 \cdot 3)$ & $25(41.7)$ & $35(58.3)$ \\
\hline Type B & 23 & $8(34.8)$ & $15(65.2)$ & $8(34.8)$ & $15(65.2)$ \\
\hline Type A & 2 & $\mathrm{O}(\mathrm{O})$ & $2(100.0)$ & $1(50.0)$ & $1(50.0)$ \\
\hline $\mathrm{P}$ & & 0.050 & & 0.910 & \\
\hline
\end{tabular}

Based on table 6 , it is known that in 2013, there was a tendency that the better the type of hospital the fewer success rates of pulmonary TB treatment. Where in type D with good success, there were $68.0 \%$, type $\mathrm{C}$ with good success there were $56.7 \%$, type B with good success there were $34.8 \%$, and type A with good success none (0.0\%). The value of $p=0.050$, which means that there were differences in the success rates of pulmonary TB treatment in 2013 based on the type of hospital in which type $\mathrm{D}$ was better than the others in 2013.

In 2016, there was a tendency that the better type of hospital the higher the success rate of pulmonary TB treatment in which in type $\mathrm{D}$ with the success of good categories there were $36.0 \%$, type $\mathrm{C}$ with good success there were $41.7 \%$, type B with good success there were $34.8 \%$, and type A with good success there were 50.0\%. The value of $p=0.910$, means that there was no difference in the success rate of TB treatment in 2016 based on the type of hospital.

\section{DISCUSSION}

The checklist of the Ministry of Health Republic of Indonesia's Subdit was an embryo for RS accreditation assessment based on the TB program. There were seven checklist points assessed, namely: commitment and organization of the DOTS Hospital team, patient discovery, treatment, medical supervision, reporting of records, internal/external networks, and health facilities (MOH RI, 2010). This study only assessed five factors associated with the success rate of TB control. This was due to factors of patient discovery and recording of reporting too far to be associated with success rates. These two factors may relate to the CDR.

\section{Sample characteristics}

Based on the results of the SITT report, there were several things that need to be evaluated. 158 hospitals were recorded and only 110 data could be processed. There were several hospitals that report zero. From the confirmation results, a zero value was obtained because the hospitals had not yet reported to SITT. Some do not know how to get an account and upload data to the SITT system. Zero results made data unable to be processed.

In general, the results of the Ministry of Health TB Subdit's view list in 2010 were low. This might be due to the unpreparedness of the hospital in implementing the TB program to the maximum in accordance with the managerial program expected by the government through the ministry of health. One of the backgrounds of the issuance of this checklist is that the potential of hospitals to treat TB patients is quite large. The hospital had handled TB patients since a long time ago, but the handling of patients was not optimal, recording and reporting activities had not been implemented properly.

The success of the TB control program with the DOTS strategy required the 
commitment of all parties including the commitment of the hospital director and his staff and medical committee along with all its members. The managerial guidelines for the service of TB patients with the DOTS strategy in the Hospital compiled by the Dirjen Special TB / RS Subdivision of Medical Services are expected to be applied by all hospitals, given that $\mathrm{TB}$ patient services with the DOTS strategy would later be included in hospital accreditation, which was planned to take effect at the beginning of the year 2011.

Assessment has been carried out to hospitals both government and private to find out the readiness of hospitals in implementing TB prevention programs. The assessment results need to be socialized, with the intention of gaining support from policy makers in improving performance in program implementation. Without the support of the management and the professions in the hospitals, the DOTS strategy will not be able to run optimally. The success rate of TB treatment in 2016 was lower than that of in 2013. This may relate to the previously poorly recorded and reporting system. This poor recording causes cases that may not be reported (underreporting). As written in the 2016 Global tuberculosis report, the national TB prevalence survey in Indonesia after 2013 showed an increase in the rate of reporting of detected TB cases (WHO, 2016).

\section{The effect of the commitment and organization of the DOTS Hospital team on treatment success rates}

The assessment of DOTS hospital team commitment and organization according to the TB Subdit list of the Ministry of Health was based on nine points, namely there was a DOTS hospital team complete with job descriptions, DOTS hospital team functions optimally, hospitals had trained personnel, TB hospital services were included in hospital medical service standards (SPM RS) and described in standard operational procedures (SOP), hospitals provided operational funds for the DOTS Hospital team, all TB RS cases were managed according to DOTS, there was a special TB hospital policy supporting DOTS, there was a TB-HIV collaboration flow, and there was an RS infection control team.

The combination of organizational commitment and relevant policies in hospitals and TB programs was needed to strengthen the implementation of DOTS in hospitals. The policy implementation process must have a clear legal basis so as to ensure compliance with field officers and target groups, as well as support from stakeholders and the commitment and expertise of policy implementers so that policy implementation can be successful. Government commitment and willingness were the most important elements in implementing DOTS programs in the private sectors. National Tuberculosis Programs were responsible for funding, technical support, training, equipment, and medicines.

The results of a study by Lonnorth et al. (2004) in India proved that the successful implementation of TB control PPM was influenced by the existence of regulations governing partnerships, the commitment of government implementing DOTS, the existence of government funding, and education and training for the private sector (Tondong, 2012 )

In this study, the commitment and organization of the DOTS Hospital team were not significantly associated with the the success rate of TB treatment. Commitment variables tended to be a protective factor of the success of pulmonary TB treatment $(\mathrm{OR}=0.43 ; 95 \% \mathrm{CI}=0.13$ to 1.38$)$ in 2013 and $(\mathrm{OR}=1.19 ; 95 \% \mathrm{CI}=0.38$ to 3.72$)$ in 2016. From the data, it was found that 
Journal of Epidemiology and Public Health (2019), 4(4): 283-295

https://doi.org/10.26911/jepublichealth.2019.04.04.03

the majority of hospital commitments were low, only 14 hospitals had a value of $\geq 80 \%$ both in 2013 and 2016. The commitment tended to be better, the lower the success rate, although not significant with the value $\mathrm{p}>0.050$. This was not in accordance with Rahman and Mokhtar (2015). Rahman and Mokhtar identified lack of basic management participation and differences in TB management in each state that would influence the success rate of TB control programs. The better management will increase the success rate.

\section{The effect of treatment on the treatment success rates}

Components assessed on the TB list included nine points, namely TB therapy according to standards in all service units, OAT packages / prescriptions included in the RS formulary, OAT procurement planing in hospitals, OAT program 1 package for patients, OAT available outside the OAT program, OAT outside meets needs, there was an MDR-TB management SOP, there was an SOP for TB-HIV management, and there was KDP therapy for HIV patients.

Tirtana' study (2011) connects the success rates with patient factors which include regularity of treatment, duration of treatment, level of income, type of work, smoking habits, distance of patient's residence to the place of treatment, and nutritional status. The results of the study show that there is an influence between regularity of treatment and length of treatment on treatment success (Tirtana et al, 2018). The Kodim in 2000 stated that the treatment performance of the DOTS strategy treatment program at the public health center level was not in accordance with the prescribed medication guidelines. As a result, the recovery rate of sufferers is far below the target (Kodim, 2000). This difference may be due to TB reporting not mentioning whether there was a drug- resistant TB. It was because the given regimen will certainly be different from first-line therapy. This would affect the success of treatment.

\section{The effect between treatment supervision and treatment success rates}

The list of TB Subdit assesses that supervision was based on six points, namely that the hospitals had an SOP for TB treatment supervision, all TB patients were accompanied by PMO (supervisors taking medication), counseling at PMO, repeated phlegm checks, follow-up on irregular treatment, and history taking source of transmission/ home contact. In this study, the treatment supervision was not significantly associated with the success rate of $\mathrm{TB}$ treatment. Treatment supervision variables in 2013 tended to be a supporting/ risk factor for the success of pulmonary $\mathrm{TB}$ treatment $(\mathrm{OR}=1.72 ; 95 \% \mathrm{CI}=0.58$ to 5.03$)$ and in 2016 as a protective factor $(\mathrm{OR}=0.60 ; 95 \%$ $\mathrm{CI}=0.19$ to 1.85 ). Despite the low significance, this was not too surprising, because indeed based on previous studies there were some differences regarding this matter.

Based on the study of Soesilowati and Haitamy (2016), TB patients with good PMO are more likely to recover in which TB patients recovered with PMO who worked well amounting to 36 people (60.00\%) and poor PMO five people (8.33\%). The group that failed treatment with a good PMO was 10 people (16.67\%) and PMOs with 9 jobs were bad (15.00\%). The group that applied the DOTS strategy with the supervision of the PMO, the drop out rate of treatment tended to be lower so that pulmonary TB patients received a complete recovery. The recovery of pulmonary TB patients can be achieved by the PMO who monitors and reminds pulmonary TB patients to take medication regularly. Supervisors taking 
medication were very important to assist patients in order to achieve optimal results. Supervisors taking medication can be from family or not family. The PMO strategy in the DOTS program can increase the success of pulmonary TB treatment as reflected in the increase in conversion rates and cure rates and a decrease in drop out rates (Soesilowati, 2016).

In contrast to Ramadhani (2012), which stated that the presence of PMO in the treatment of pulmonary TB on AFB conversion was not statistically significantly different $(\mathrm{p}=$ 0.699). This might be caused by the absence of information on TB bacillus resistance factors for TB drugs, the number of subjects that were too small, the sampling was done retrospectively from secondary data, and several other factors that could not be identified in the study. This factor can affect the success of conversion such as patient's immune system, comorbidities in patients, drug side effects, drug resistance, socio-economic, nutrition, distance home and education (Ramadhani, 2012).

It is possible that PMO in TB patients is not the same in knowledge of OAT supervision and assistance. It was because the data did not include PMO standardization. These different abilities can cause different treatment results. As mentioned in previous studies, there are differences in results between PMOs who work well and PMOs that work poorly (Soesilowati, 2016). In addition, there was a theory that compliance with medication was more important than the presence of PMO because TB patients who regularly adhere to medication time and control show more of the patient's willingness or awareness to participate in achieving treatment success (Ramdhani, 2018).

\section{The effect of internal/external net- works on the treatment success rates}

Networks assessed on the TB Subdit view list included the establishment of internal networks with their SOPs, hospital activity in external networks, TB case references from all SMFs in hospitals, monitoring of absent/displaced TB cases, DOTS-VCT collaboration, DOTS internal networking meetings periodically, and the presence of hospitals in external network meetings.

Internal / external networks were not significantly related to the success rate of TB treatment. Nominally, the external internal network variable in 2013 tended to be a supporting factor/risk of the successful treatment of pulmonary TB $(\mathrm{OR}=1.04 ; 95 \%$ $\mathrm{CI}=0.29$ to 3.63 ). The better the network, the better the success rate. In 2016, it tended to be a protective factor in the success of pulmonary $\mathrm{TB}$ treatment $(\mathrm{OR}=$ $0.55 ; 95 \% \mathrm{CI}=0.13$ to 2.21 ). Tondong et al. (2012) investigated that the implementation of PPM TB control in Ende Regency, East Nusa Tenggara had not run optimally. One of the factors that influence the low success of TB control was because the network did not function properly. Internal networks not functioning properly can be caused by: 1) lack of commitment of hospitals management in the implementation of DOTS in hospitals, 2) DOTS team did not work optimally due to high workloads or multiple tasks, 3) there were no special DOTS units in TB services comprehensive in hospitals, causing difficulties in coordination between units and external networks, and 4) lack of communication and coordination between internal network units (Tondong et al, 2014).

The external PPM TB control network did not function properly due to: (1) lack of communication and coordination between the PPM network for TB case holding cases, 
(2) unclear referral mechanisms and lack of collaboration support between health facilities in TB patient referrals such as referral do not use a referral letter (ТВ 09), the results of a laboratory examination (TB 05 ); (3) no fluency in the referral process (the reference form, list of names and telephone numbers of staff in charge of health facilities), and (4) the health office who had not played an active role in coordinating the PPM network (Tondong et al, 2014).

The holding case process was mainly commitment, a good system and communication to achieve successful treatment, and the Hospital cannot achieve good quality performance without the right network with the public health centers (Probandari et al, 2010). The network can run well, it requires a DOTS network coordinator who worked full time, the active role of supervisors, clear networking mechanisms between institutions, the availability of tools to facilitate the referral process, support and cooperation between health facilities in TB patient referral activities, regular coordination meetings at least every three months between health facilities coordinated by the health department by involving all other parties involved. For this reason an effective referral system must be established between service units. Locally, appropriate referral mechanisms and resources to monitor referrals and ensure patients diagnosed with TB do not break up after being referred for treatment (Tondong et al, 2014).

\section{The effect of equipment facilities on treatment success rates}

The list of TB Subdit assessed the equipment facilities based on: there was a DOTS hospital room, the DOTS Hospital room meets infection control requirements, there was an inpatient room for TB cases, a standard TB form is available, laboratory facilities are complete, and there were extension facilities. Niarta's (2004) study states that laboratories can influence treatment success rates. The number of laboratory errors below the maximum error rate is caused by a lack of supervision of quality, motivation, and employee compliance in examining sputum specimens. In addition, there is also a lack of training of laboratory staff in sputum examinations (Niarta et al, 2004). Facilities for equipment facilities were not significantly related to the success rate of TB treatment.

\section{The effect of types of hospitals on the treatment success rates}

Type of hospital was significantly associated with treatment success rates in 2013 in which the lower type of hospital, the better the success rate of TB treatment. Some things might cause this situation. First, a reporting system according to WHO reports was not good. The second is the complexity of the hospital. The higher the type of hospital, the more complex cases handled, including in this case the TB problem. The lower the type of hospital, the simpler the cases handled. So that, the success rate for type D hospitals is better than type C, B or A. Hospital in 2016 the type of hospital was not associated with treatment success rates.

The results of this study tended to prove that there was no significant relationship between commitment and organization of the DOTS Hospital team, treatment, and supervision of medication, internal / external networks, and health facilities with the success rate of TB treatment. Type of hospital is significantly associated with treatment success rates in 2013. The lower the type of hospital, the lower the level of complexity of TB problems, the better the success rate of $\mathrm{TB}$ treatment.

Based on these results, the possibility of instruments compiled by the Ministry of Health TB Subdit in 2010 was not yet sensitive enough to be a predictor of treatment 
success rates. This instrument was not made for research, but only as monitoring and evaluation, so that it cannot be used as an appropriate predictor. The 2010 checklist as the goal was the basic starting point for the assessment of hospital accreditation. At that time, there was no pressure or burden on the hospital to make a good program or managerial management of TB in the hospital, because there were indeed no more consequences than the assessment carried out. This was different from managerial assessments associated with accredittation in which the next result would determine the class or type of hospital. Therefore, if the evaluation results of the checklist are linked to the success rate of the hospital, it may not be related. Possible results would be different if the success rate of TB treatment is linked to the results of hospital accreditation. The assessment was done not only once but regularly. However, to get the results of evaluating the implementation of TB programs based on the value of accreditation, it still seems difficult Given that the results of RS accreditation are currently based on general hospital assessments, it was not specific to TB prevention programs.

The success rate of TB treatment in 2016 was lower compared to 2013. This may be related to a poor recording and reporting system. This poor record-keeping results in cases that may not be reported (under-reporting) the difference in the number of cases in health care facilities with reporting results (missing cases). To ensure this condition, a study by identifying the risk factors that influence it further needs to be conducted.

Based on the results of this study, it was shown that most hospitals had a poor success rate $(<85 \%)$ in 2013 , and even in 2016 fewer hospitals achieved good success rates.
There was no relationship between commitment and organization of the DOTS Hospital team, treatment, treatment supervision, internal / external networks, and equipment facilities with treatment success rates in 2013 and 2016. Type of hospital was significantly associated with treatment success rates. The lower the type of hospital, the better the success rate of TB treatment.

\section{AUTHORS CONTRIBUTION}

Reviono, Yusniar Ramadhiana, Ari N Probandari, and Wahyu Setianingsih collected the data, measured hospital performance, did data analysis, examined success rate of TB control, and wrote the manuscript.

\section{CONFLICT OF INTEREST}

The authors declare there is any conflict of interest.

\section{FUNDING AND SPONSORSHIP}

There is no external funding or sponsorship.

\section{ACKNOWLEDGEMENT}

We would like to thank Central Java Provincial Health Office and hospitals in Central Java for giving permission to collect the data.

\section{REFERENCE}

Doucette K, Cooper R (2015). Tuberculosis. In: Fishman JA, Elias JA, Grippi MA, Senior RM, Pack AI, Kotloff RM Editors. Fishman's pulmonary diseases and disorders. 5th ed. New York: The McGraw-Hill Companies Inc.

World Health Organization (2016). Global tuberculosis report. Retrieved from http://www.who.int/tb/publications/ global_report/en/

Kundu D, Chopra K, Khanna A, Babbar N, Padmini TJ (2016). Accelerating TB notification from the private health 
Journal of Epidemiology and Public Health (2019), 4(4): 283-295

https://doi.org/10.26911/jepublichealth.2019.04.04.03

sector in Delhi, India. Indian J Rheumatol. 63(1): 8-12.

Ministry of Health of RI (2017). Tuberkulosis temukan obati sampai sembuh (Tuberculosis, find, treat, cured). Retrieved from http://www.depkes.go.id/download.php?file=download/p usdatin/infodatin/InfoDatin-2016TB.pdf.

Irawati SR, Basri C, Arias MS (2007). Hospital DOTS linkage in Indonesia: a model for DOTS expansion into government and private hospitals. Int J Tuberc Lung Dis. 11(1): 33-9.

Ministry of health of RI (2010). Pedoman manajerial pelayanan tuberkulosis dengan strategi DOTS di RS (Managerial guidelines for tuberculosis services with DOTS strategies in hospitals). Jakarta: Kementrian Kesehatan RI.

Tondong MAP, Mahendradhata Y, Ahmad RA (2014). Evaluasi implementasi public private mix pengendalian tuberkulosis di Kabupaten Ende Provinsi Nusa Tenggara Timur tahun 2012 (Evaluation of the implementation of tuberculosis control public private mix in Ende Regency, East Nusa Tenggara Province in 2012). J Kebijakan Kesehatan Indonesia. 3(1): 37-42.

Tirtana B, Musrichan (2018). Faktor- faktor yang mempengaruhi keberhasilan pengobatan pada pasien tuberkulosis paru dengan resistensi obat tuberkulosis di wilayah Jawa Tengah (Factors that influence the success of treatment in pulmonary tuberculosis patients with tuberculosis drug resistance in the Central Java region). Retrieved from https://eprints.undip.ac.id/32879/1/Bertin.pdf.

Kodim N (2000). Kinerja pengobatan program pemberantasan TBC strategi DOTS di Propinsi Sumsel Jabar, Ja- teng, dan Sulteng 1998-1999 (Treatment performance of DOTS strategy TB eradication program in West Sumatra, Central Java, and Central Sulawesi Province of South Sumatra 1998-1999). Medika. 8: 493-504.

Soesilowati R, Haitamy MN (2016). Perbedaan antara kesembuhan pasien tb paru dengan pengawas minum obat (PMO) dan tanpa PMO di RSUD Prof. Dr. Margono Soekarjo (The difference between the recovery of pulmonary $\mathrm{TB}$ patients and supervisors taking medication (PMO) and without PMO at Prof. Dr. Margono Soekarjo hospital). Sainteks. 13(1): 50-60.

Ramadhani A (2012). Pengaruh pelaksanaan pengawas menelan obat (PMO) terhadap konversi BTA (+) pada pasien tuberkulosis paru di RSDK tahun 2009/2010 (Effect of the implementation of drug swallow control (PMO) on smear $(+)$ conversion in pulmonary tuberculosis patients in RSDK in 2009/2010). Retrieved from https://ejournal3.undip.ac.id/index.p $\mathrm{hp} /$ medico/article/view/1497.

Probandari A, Lindholm L, Stendlud H, Utarini A, Hurting AK (2010). Missed oportunity for standardrized diagnosis and treatment patients in hospital involved in public privat mix for directly observed treatment shortcourse strategy in Indonesia, BMC Health Services Research Journal. 10:1-6.

Niarta W, Supardi S (2004). Evaluasi dampak intervensi manajemen program pemberantasan toberkulosis oleh World Vision Indonesia (WVI) di Kabupaten Timor Tengah Utara (Evaluation of the impact of the tuberculosis eradication program management intervention by World Vision Indonesia in North Timor Tengah 
Reviono et al./ Factors Associated with Success Rate for TB Treatment

District). Sains Kesehatan. 17(3):32337.

Rahman N, Mokhtar KS (2015). Challenges of national TB control program imple- mentation: the Malaysian experience.

Procedia-Soc Behav Sci.172:578-84. 